\title{
Proximal partial fibular resection instead of total knee prosthesis in a patient with metal allergy
}

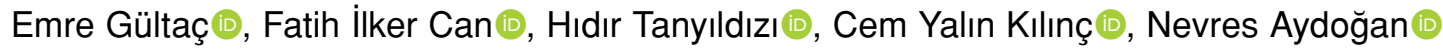 \\ Department of Orthopedics and Traumatology, Muğla Sıtkı Koçman University Faculty of Medicine, Muğla, Turkey
}

Knee osteoarthritis is a common joint disease affecting middle-aged and elderly individuals. ${ }^{[1]}$ High tibial osteotomy (HTO), unicompartmental or total knee arthroplasty (TKA) can be preferred as surgical treatment modalities in patients with medial compartment arthrosis. These methods are usually determined according to the age of the patient, the degree of medial arthrosis, the presence of arthrosis in the lateral compartment, and the experience of the surgeon. All of these surgical treatment options require metallic biomaterials such as stainless steels, titanium alloys, and cobalt-chromium alloys. According to the patch test and blood analysis, the frequency of nickel, cobalt, chromium skin allergies in the general population is $13 \%, 2 \%$ and $1 \%$, respectively. Although metal hypersensitivity is estimated between 10 to $15 \%$ in the general population, even higher incidences may be observed up to $25 \%$. $^{[2]}$

Received: October 25, 2021

Accepted: December 20, 2021

Published online: December 22, 2021

Correspondence: Emre Gültaç, MD. Muğla Sıtkı Koçman Üniversitesi Tıp Fakültesi, Ortopedi ve Travmatoloji Anabilim Dalı, 48000 Muğla, Türkiye.

E-mail: emregultac@yahoo.com

Doi: 10.52312/jdrscr.2022.13

Citation: Gültaç E, Can Fi, Tanyıldızı H, Kılınç CY, Aydoğan N. Proximal partial fibular resection instead of total knee prosthesis in a patient with metal allergy. Jt Dis Relat Surg Case Rep 2022;1(1):35-38

(02022 All right reserved by the Turkish Joint Diseases Foundation

This is an open access article under the terms of the Creative Commons Attribution-NonCommercial License, which permits use, distribution and reproduction in any medium, provided the original work is properly cited and is not used for commercial purposes (http://creativecommons. org/licenses/by-nc/4.0/).

https://www.casereportsjointdrs.org

\section{ABSTRACT}

A 66-year-old female patient with Grade III osteoarthritis was considered for primary total knee arthroplasty (TKA). Due to her metal allergy, TKA was abandoned and proximal partial fibular resection (PPFR) was planned. The patient was evaluated at regular follow-ups. Based on the Western Ontario and McMaster Universities Osteoarthritis Index (WOMAC) and Visual Analog Scale (VAS) scores, a significant improvement, particularly in terms of pain and functional scores with limited radiological change, was observed. In conclusion, the PPFR is a viable surgical treatment option in patients with gonarthrosis who have metal hypersensitivity.

Keywords: Medial release, metal allergy, metal hypersensitivity, osteoarthritis, proximal partial fibular resection.

In the literature, the frequency of cutaneous reactions due to metallic implants has been reported at rates ranging from $<0.1$ to $5 \% \cdot{ }^{[3]}$ Due to these reactions, the relationship between metal hypersensitivity and implant failure has been the subject of research in many studies in recent years. ${ }^{[4]}$

Proximal partial fibular resection (PPFR) has been emerging as a viable option which is an easier, less invasive and proposedly cheaper surgical treatment method than HTO and TKA in recent years. ${ }^{[5]}$ On the other hand, PPFR technique has a risk of peroneal nerve damage, if the nerve is not dissected and protected properly. ${ }^{[5]}$ It does not require bone union and implant usage; therefore, there is no risk of metal hypersensitivity which was the main purpose of our PPFR application. ${ }^{[6]}$ Herein, we report a case of gonarthrosis having metal allergy in whom the PPFR technique was used as an alternative surgical method.

\section{CASE REPORT}

A 66-year-old female patient was admitted to our clinic with pain in both knees. Upon physical 


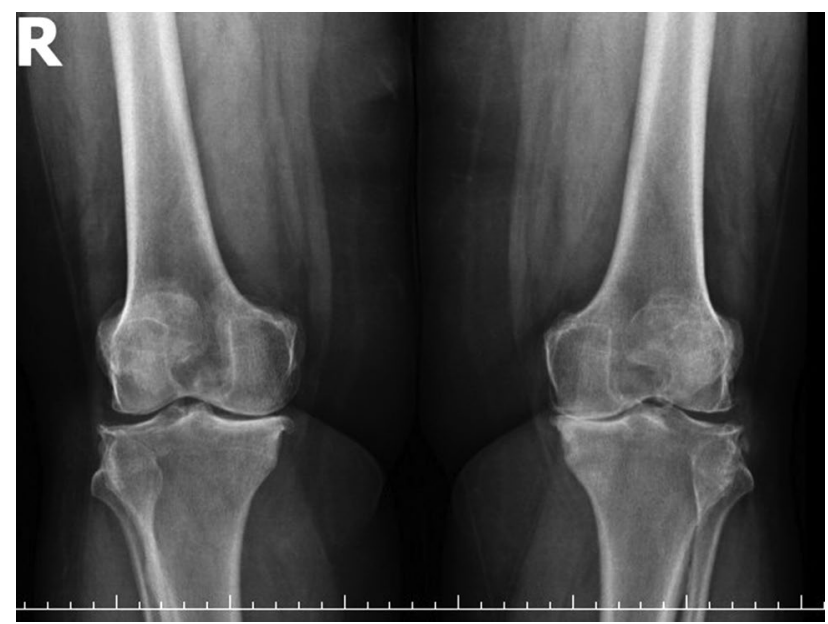

Figure 1. The preoperative bilateral weight-bearing knee X-ray.

examination, limited flexion of $95^{\circ}$ in both knees was apparent. Grade III osteoarthritis was detected according to the Kellgren-Lawrence classification on weight-bearing X-ray radiographs (Figure 1). The patient was considered for primary TKA; however, after obtaining a detailed medical history, her allergic reaction to metal jewelry was detected. Dermatology consultation was requested to determine the severity of the allergic reaction to metallic implants. The skin patch test revealed that the patient had a + (erythema + infiltration) reaction at $48 \mathrm{~h}$ and a ++ (erythema + infiltration + papule) reaction at $96 \mathrm{~h}$. Diagnostic criteria for metal hypersensitivity reactions to metallic implants were examined in terms of patch tests findings. ${ }^{[7]}$ Nickel and molybdenum measurements were within the normal range in the blood tests.

Due to the allergic condition of the patient, TKA was abandoned and PPFR and medial ligament complex release were planned for both knees, abolishing implant requirement. The patient was informed about

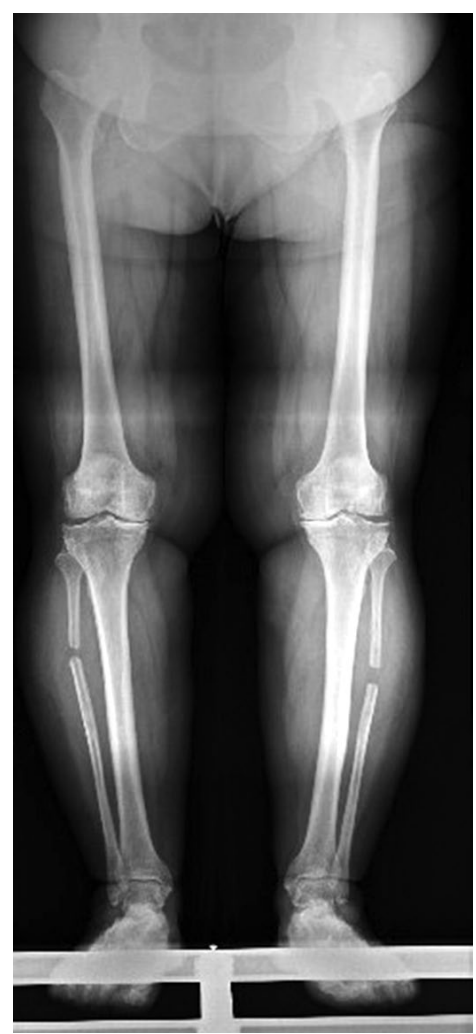

Figure 2. The postoperative weightbearing orthoroentgenogram at first year of follow-up.

the surgery complications including the risk of nerve injury and a written informed consent was obtained.

Both lower limbs were prepared for surgery. To loosen the peroneal nerve, a sterile roller was placed under the knee in $40^{\circ}$ flexion position. A posterolateral incision was made approximately 6 to $10 \mathrm{~cm}$ below the proximal end of the fibula, depending on the patient's height. Peroneal nerve was dissected and protected. Approximately 1 to $1.5 \mathrm{~cm}$ bone resection was performed on the proximal fibula using an

TABLE I

Pre- and postoperative measurement and score values of the patient

\begin{tabular}{|c|c|c|c|c|c|c|c|c|c|c|}
\hline & \multicolumn{2}{|c|}{ Preoperative } & \multicolumn{2}{|c|}{$\begin{array}{l}\text { Postoperative } \\
1^{\text {st }} \text { month }\end{array}$} & \multicolumn{2}{|c|}{$\begin{array}{l}\text { Postoperative } \\
3^{\text {rd }} \text { months }\end{array}$} & \multicolumn{2}{|c|}{$\begin{array}{l}\text { Postoperative } \\
6^{\text {th }} \text { months }\end{array}$} & \multicolumn{2}{|c|}{$\begin{array}{c}\text { Postoperative } \\
1^{\text {st }} \text { year }\end{array}$} \\
\hline & Left & Right & Left & Right & Left & Right & Left & Right & Left & Right \\
\hline VAS & 6 & 8 & 2 & 2 & 2 & 2 & 2 & 3 & 4 & 2 \\
\hline WOMAC & 54.1 & 69.7 & 14.5 & 16.6 & 17.7 & 16,6 & 17.7 & 19,7 & 32,2 & 14,5 \\
\hline Medial joint space $(\mathrm{mm})$ & 0.4 & 0 & 0.6 & 0.3 & 0.5 & 0.3 & 0.5 & 0.3 & 0.4 & 0.3 \\
\hline Lateral joint space $(\mathrm{mm})$ & 9 & 10 & 8 & 8 & 8 & 8 & 7 & 8 & 7 & 8 \\
\hline Femorotibial angle & 181 & 183 & 178 & 180 & 178 & 179 & 177 & 179 & 178 & 178 \\
\hline
\end{tabular}

VAS: Visual Analog Scale; WOMAC: Western Ontario and McMaster Universities Osteoarthritis Index. 
oscillating bone saw. Then, percutaneous pie-crust technique was performed to the superficial medial collateral ligament (sMCL) from the tibial attachment site to the deep medial collateral ligament (dMCL) at the joint level with an 18-gauge needle. The patient was mobilized on the first postoperative day as much as she could tolerate.

The patient was evaluated at postoperative 1, 3, 6, and 12 months. At the postoperative first year, the Western Ontario and McMaster Universities Osteoarthritis Index (WOMAC) and Visual Analog Scale (VAS) scores were examined (Table 1). The medial and lateral joint space and femorotibial angle were examined on the standing anteroposterior radiographs (Figure 2). There was a significant improvement, particularly in terms of pain and function according to VAS and WOMAC, with a limited radiological change (Table I).

\section{DISCUSSION}

Biomechanically, knee osteoarthritis is caused by an imbalance between biological resistance and mechanical stress. In patients with varus deformity, pain is more pronounced in the medial compartment. The main goal in all surgical treatments is to correct the axis. Although causes of pain relief after fibular osteotomy are not fully explained, it is thought that it develops due to the correction of the alignment. ${ }^{[8]}$ Fibular osteotomy was coincidentally described in prisoners with medial knee arthritis in the early 2000s, with relief of symptoms after proximal fibular fractures during riots. Although the term proximal fibular osteotomy (PFO) is commonly used in the literature, we chose to use the PPFR, as this technique is more likely a resection than an osteotomy. ${ }^{[6]}$

The first study on PFO was published by Yang et al. ${ }^{[8]}$ in 2015 showing the improvement in the radiographic and functional results of 110 patients with a follow-up period of more than two years. They reported two common peroneal nerve palsies and two superficial peroneal nerve injuries which resolved within 3 to 10 months. ${ }^{[8]}$ With this technique, we performed our first case in our clinic in the same year and have applied this surgical procedure to more than 50 patients until now. The main idea in this procedure is that, although the medial part has only one cortex support, there are three cortex supports (one tibia + two fibulae) lateral to the knee. With partial resection, the main goal is to weaken the lateral fibular support and reduce varus deformity. In varus deformity, we added percutaneous pie-crust technique to the surgical procedure to loosen the tense soft tissue in the medial compartment.

The advantage of this technique is that it is easy to apply and does not require implant usage. Considering the metal allergy of our patient, we preferred this technique to eliminate metallic implant requirement.

The relationship between metallic implants with dermatitis has been known for nearly four decades. Several studies on localized or systemic skin reactions that persist after TKA have also been reported in the dermatology literature. ${ }^{[9,10]}$ Therefore, dermatology consultation is recommended for patients who develop chronic dermatitis without concomitant knee synovitis or component loosening. In the last few years, numerous studies of persistent synovitis with severe pain in patients with components of cobalt-chromium TKA have also been reported. ${ }^{[10]}$ Pathological specimens of patients undergoing revision TKA due to metal hypersensitivity revealed lymphoplasmacellular and eosinophilic fibrous tissue, synovial hypertrophy and hyperplasia, and chronic histiocytic reaction. After revision surgeries, which were performed by changing the type of metallic implant, an improvement in the functions of the patients was observed; however, the regression of the dermatitis was occasionally poor. ${ }^{[10]}$ Due to these concerns, preferring a different surgical method rather than arthroplasty seems to be reasonable in patients with metal allergy.

The postoperative clinical and radiological improvements of our patient were satisfactory. A significant improvement in pain scores, particularly on the first postoperative day, was remarkable. Although radiological improvement was limited, the relief of symptoms and functional scores were preserved one year after the operation. Of note, utmost care should be taken to identify and preserve the common peroneal nerve that runs from proximal to distal during surgery. Accordingly, the dissection plane to approach the fibula and the resected fibula area are critical. The PPFR technique carries a risk of peroneal nerve damage, if the nerve is not properly dissected and preserved. ${ }^{[5]}$ In surgical treatment of osteoarthritis, the PPFR technique may be a viable surgical treatment option in patients with gonarthrosis who have metal hypersensitivity. In such cases, attention should be paid to protect the common peroneal nerve.

\section{Declaration of conflicting interests}

The authors declared no conflicts of interest with respect to the authorship and/or publication of this article. 


\section{Funding}

The authors received no financial support for the research and/or authorship of this article.

\section{REFERENCES}

1. Atik OS. Can we treat knee osteoarthritis with photomedicine? Photomed Laser Surg 2015;33:121-2.

2. Schäfer $T$, Böhler E, Ruhdorfer $S$, Weigl L, Wessner D, Filipiak B, et al. Epidemiology of contact allergy in adults. Allergy 2001;56:1192-6.

3. Merritt K, Rodrigo JJ. Immune response to synthetic materials. Sensitization of patients receiving orthopaedic implants. Clin Orthop Relat Res 1996;(326):71-9.

4. Thyssen JP, Johansen JD, Menné T, Lidén C, Bruze M, White IR. Hypersensitivity reactions from metallic implants: A future challenge that needs to be addressed. Br J Dermatol 2010;162:235-6.

5. Shanmugasundaram S, Kambhampati SBS, Saseendar S. Proximal fibular osteotomy in the treatment of medial osteoarthritis of the knee - A narrative review of literature. Knee Surg Relat Res 2019;31:16.

6. Gültaç E, Tanyıldızı H, Kılınç C, Aydoğan N. Diz osteoartriti cerrahi tedavisinde alternatif tedavi yaklaşımı: Proksimal parsiyel fibular rezeksiyon yapılan hastalarımızda erken dönem sonuçlarımız. Muğla Sıtkı Koçman Üniversitesi Tıp Dergisi 2019;6:152-4.

7. Schalock PC, Thyssen JP. Patch testers' opinions regarding diagnostic criteria for metal hypersensitivity reactions to metallic implants. Dermatitis 2013;24:183-5.

8. Yang ZY, Chen W, Li CX, Wang J, Shao DC, Hou ZY, et al. Medial compartment decompression by fibular osteotomy to treat medial compartment knee osteoarthritis: A pilot study. Orthopedics 2015;38:e1110-4.

9. Verma SB, Mody B, Gawkrodger DJ. Dermatitis on the knee following knee replacement: A minority of cases show contact allergy to chromate, cobalt or nickel but a causal association is unproven. Contact Dermatitis 2006;54:228-9.

10. Anand A, McGlynn F, Jiranek W. Metal hypersensitivity: Can it mimic infection? J Arthroplasty 2009;24:826.e25-8. 